\title{
Dynamic Input Output Analysis: Carbon, Water and Ecological Hierarchy
}

\author{
J. Z. $\mathrm{Li}^{1}$ and S. C. $\mathrm{Li}^{2}{ }^{*}$ \\ ${ }^{1}$ State Key Joint Laboratory of Environmental Simulation and Pollution Control, School of Environment, Beijing Normal University, \\ Beijing 100875, China \\ ${ }^{2}$ College of Humanities, Yantai University, Yantai 264005, China
}

Received 25 February 2021; revised 10 April 2021; accepted 27 June 2021; published online 16 August 2021

\begin{abstract}
Fossil fuel combustion and industrial process would lead to substantial carbon emissions. Carbon emission metabolism is essential for alleviating climate changes globally. Here, a dynamic input-output model is developed for analyzing carbon emission metabolism and ecological hierarchy. Both direct and indirect carbon emissions are evaluated, and mutual relationships between various sectors are explored. Novelties of this research are summarized as follows: firstly, for negative ecological elements, e.g., carbon emissions, production activities between sectors with competition relationship should be encouraged since its positive effects in emission mitigation. On the contrary, interferring production activities between sectors with mutualism relationships would help to carbon abatement. Moreover, analysis of indirect carbon emissions could identify the embodied sectors with large emissions, and these sectors should adjust their production structures and upgrade the cleaner production technology. In addition, ecological hierarchy analysis would help to identify key sectors lacking driving or pulling force during study period. It provides a new insight into formulating or maintaining a healthy ecological system. Results show that carbon emissions mainly concentrated in electricity-generation, manufacturing, and transportation sectors. For the Province of Guangdong, electricity-generation and mining sectors should upgrade the cleaner production technologies. Substitution for renewable energy would accelerate the green transition within power system. For construction sector with large indirect carbon emissions, adjusting the consumption structure would contribute to achiving the emission mitigation goal. Tertiary industry is not sufficiently promoting Guangdong's economic development, and therefore plays a restrictive role in the current economy. These would support the formation of emission abatement policies.
\end{abstract}

Keywords: carbon emission, ecological network analysis, network utility analysis, ecological hierarchy, indirect emission, mutualism index

\section{Introduction}

Substantial carbon emissions have been instigated with rapid industrialization and urbanization in recent years (Zhang et al., 2018; Roberts et al., 2020; Shrestha and Wang 2020; Wu et al., 2020). With the rapid urbanization and industrialization, China holds the largest carbon emissions around the world. China's positive actions would have great impacts on achieving emission mitigation goal worldwide (Asif and Chen, 2020). It is announced that China would peak its carbon emissions by 2030 and achieve its carbon neutrality by 2060 , i.e., the goal of "3060" (Li et al., 2018). Carbon emissions are almost induced by fossil fuel combustion and industrial process (Wang et al., 2017). To achieve the goal of " 3060 " Carbon metabolism is critically desired to mitigating global climate change ( $\mathrm{Li}$ et al., 2021a).

Ecological network analysis (ENA) is an effective method to study a system's structure and functions, making it possible

\footnotetext{
* Corresponding author. Tel.: 010-5880-0156.

E-mail address: jizhelee@outlook.com (S. C. Li).
}

ISSN: 2663-6859 print/2663-6867 online

(C) 2021 ISEIS All rights reserved. doi:10.3808/jeil.202100065 to analyze the structural distribution and functional relationships within the system. Developed from the input-output model (Leontief, 1936), ENA was firstly proposed by Patten (Patten, 1992). This method could assess the goods and services between various sectors among ecological system, and analyze the corresponding interactions. Recently, most research has focused on the natural system. Analyses on systems considering socioeconomic and ecological effects is critically desired. Most of these studies only concentrated on a single sector, and interactions between various sectors are ignored. Moreover, many elements have been analyzed with the application of ENA method, i.e., virtual water (Chaudhuri et al., 2020; Wang et al., 2020a; Yu et al., 2020), energy (Abdehvand et al., 2021; Li et al., 2021b; Zhang et al., 2021b), solid waste (Guan et al., 2019; Zhang et al., 2021a), heavy-metal emission (Zheng et al., 2020, 2021), carbon (Wei and Chen, 2020; Li et al., 2021c), and wastewater (Zheng et al., 2019). For instance, Fang et al. (2013) evaluated the structure and function of virtual water system and assessed the interactions among socioeconomic sectors. Dai et al. (2014) evaluated the exergy-related flows among a socioeconomic system and provided insightful suggestions for sustainable development. Indirect emissions are assessed by Li et al. (2018) and complicated mutual relationships are evaluated 
within a carbon metabolism system. Chen et al. (2020b) developed an ENA-related model to assess the carbon metabolism globally and give carbon mitigation policies Analyses of carbon metabolism have also been conducted spatially (Chen and Chen, 2017; Chen et al., 2020a). A carbon cycle-related model has also been established (Wang et al., 2020b). Trade between economic sectors could be evaluated with ENA method.

However, there are few research on carbon emission metabolism in Guangdong Province, and most are focused on direct emissions. Input-output analysis could only reflect the local characteristics. Analysis of carbon metabolism of Guangdong Province is rare. Moreover, there is a lack of research on dynamic carbon emission metabolism. Ecological hierarchy for negative element and carbon emissions are critically desired.

Therefore, the objective of this study is to get a holistic assessment of the carbon dioxide metabolism among economic sectors of Guangdong Province, and give a comparison of ecological hierarchy from bottom-up and top-down perspectives. In detail, an ENA-related carbon metabolism model is developed to assess the healthy degree of socioeconomic system. Implied sectors with large indirect emissions would be identified and corresponding suggestions would be proposed to achieve the emission mitigation goal. Moreover, ecological hierarchy (i.e., pulling and driving force) would be assessed. This study would help to formulate target policies on emission mitigation policies.

\section{Material and Methods}

\subsection{Carbon Emission Network Model}

Carbon emission flows between various sectors could be evaluated with technical coefficient matrix and direct carbon emissions, with the convertion method derived from Leontief. A carbon metabolism system could be further developed with mutual flows between various economic sectors. For quantification purpose, the embodied carbon emission intensity should be firstly introduced to realize the conversion from monetary data to the ecological data. According to the mass theory, carbon emissions flowing into the environment is equal to the total carbon emissions eliminating the carbon emissions resulting from inter-sectoral exchange, which can be depicted by multiplying the conversion factor which can be depicted as Equation (1). The dimensionless factor can be depicted as follows:

$\mathbf{P}+\varepsilon \mathbf{H}=\varepsilon \mathbf{U}$

where $\mathbf{H}$ is intermediate matrix from the input-output table, $\mathbf{U}$ represents total output, $\mathbf{P}$ represents direct carbon emissions. In this research, carbon emission is identified as the negative ecological element. Then:

$\varepsilon=\mathbf{P}(\mathbf{U}-\mathbf{H})^{-1}$

where $\varepsilon_{i}$ is embodied emission intensity. $f_{i j}$ contains carbon dioxide flows among sectors with the direction from the production side to others on the consumption side. The sum of the total carbon emissions flowing into the sytem equals to the sum flowing out, which could be represented by the following Equation:

$T_{i}^{i n}=\sum_{j=1}^{n} f_{i j}+z_{i}, T_{i}^{o u t}=\sum_{j=1}^{n} f_{j i}+y_{i}$

where $T_{i}^{i n}$ is the total carbon inflow to sector $i$, and $T_{i}^{\text {out }}$ is total carbon outflow from $i$. $z_{i}$ and $y_{i}$ represent the boundary input and output of sector $i$ flowing into or out of the system, respectively.

\subsection{Network Utility Analysis}

Network utility analysis could evelate the mutual relationship between various socioeconomic sectors (1992). In this research, direct and integral utilty are both assessed between pairwise sectors. Direct utility could be depicted by the following Equations:

$\mathbf{D}=\left[d_{i j}\right]=\left[\frac{f_{i j}-f_{j i}}{T_{j}}\right]$

$T_{j}=\sum_{i=1}^{n} f_{i j}+Z_{j}$

where $T_{j}$ is tis the total resources or waste flowing into the system.

Integral utility matrix is utilized to assess the implied relationships between various sectors. It could be assessed by the following Equation:

$\mathbf{U}=\mathbf{U}^{0}+\mathbf{U}^{1}+\mathbf{U}^{2}+\cdots+\mathbf{U}^{l}+\cdots=(\mathbf{I}-\mathbf{D})^{-1}$

Mutualism index is defined as the ratio of positive and negative signs in the matrix $\mathbf{U}$. For negative elements, negative signs being more than positive ones indicates that the system is in a stable state. Conversely, system have large potential in metabolic disorders with more positive signs.

\subsection{Ecological Network Analysis}

Hierarchy can be reflected by ENA method. A dimentionless integral flow between pairwise sectors can be depicted by the following Equation:

$\mathbf{N}^{\prime}=\left(n_{i j}^{\prime}\right)=\left(\mathbf{G}^{\prime}\right)^{0}+\left(\mathbf{G}^{\prime}\right)^{1}+\left(\mathbf{G}^{\prime}\right)^{2}+\left(\mathbf{G}^{\prime}\right)^{m}+\cdots=\left(\mathbf{I}-\mathbf{G}^{\prime}\right)^{-1}$

where $g_{i j}{ }^{\prime}=f_{i j} / T_{i}$ is interflows from one sector to another, and $T_{i}$ is the sum of flows. Relative contribution weight $\left(W_{i}\right)$ could reflect the ability of downstream sectors to receive re- sources or waste from other sectors. It could depict the pulling force of sectors from the perspective of forward linkages. The pulling force could be calculated by the following Equation:

$W_{i}=\sum_{j=1}^{n} y_{i j} / \sum_{i=1}^{n} \sum_{j=1}^{n} y_{i j}$ 
The driving force represents the ability of upstream sectors transferring goods and services to other sectors. It could be calculated by the following Equation:

$$
W_{j}=\sum_{i=1}^{n} y_{i j} / \sum_{i=1}^{n} \sum_{j=1}^{n} y_{i j}
$$
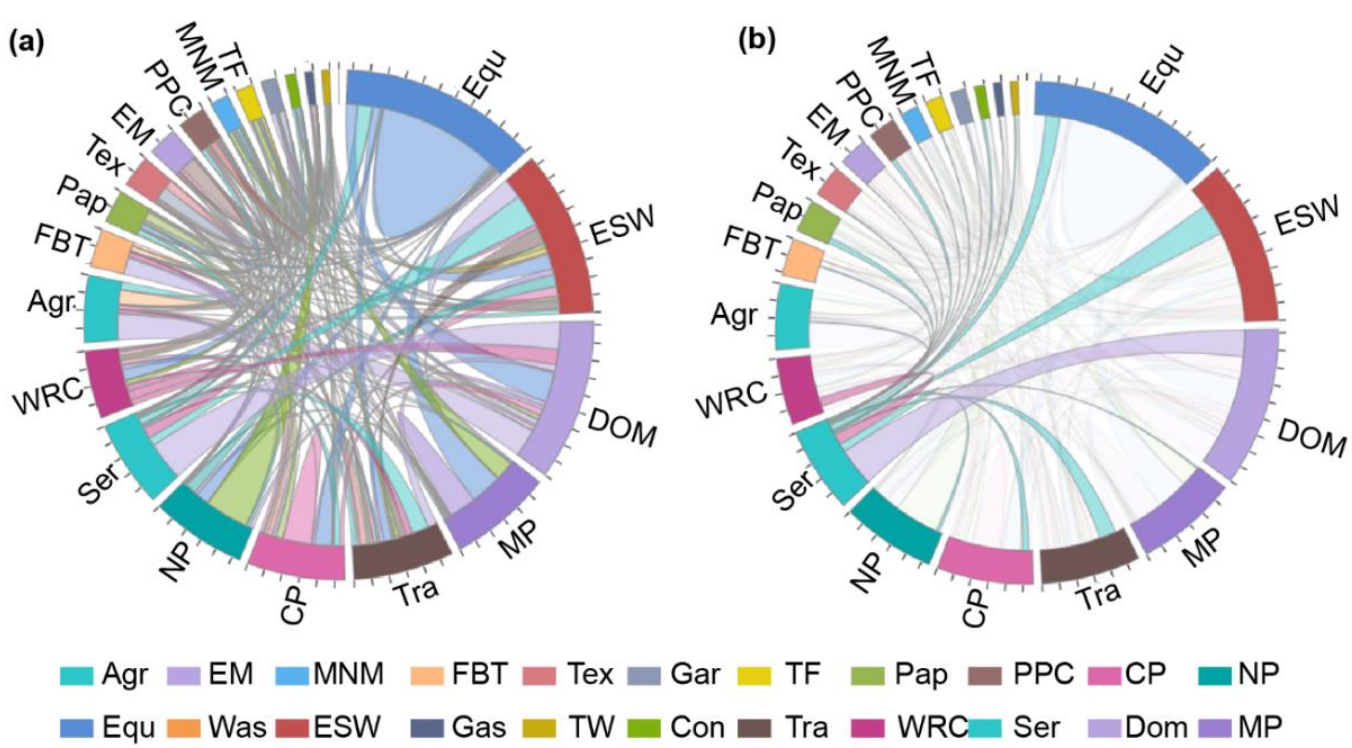

Figure 1. (a) Carbon emission flows between pairwise sectors. As shown in the legend, different colors depict various sectors. Sectors with longer arc lengths would produce more carbon emissions when communicating with other sectors. The width of the line represents the amount of emission flows, while the color represents the direction of the flow between two sectors. (b) Carbon emission flows of Ser sector with other twenty-one sectors.

Table 1. Direct Emission Intensity of Economic Sectors from 2000 to 2012

\begin{tabular}{|c|c|c|c|c|c|c|c|}
\hline & 2000 & 2002 & 2005 & 2007 & 2010 & 2012 & \\
\hline Agr & 2.93 & 2.75 & 2.96 & 1.83 & 1.47 & 1.53 & $10 \square---$ \\
\hline EM & 2.69 & 0.94 & 0.67 & 0.42 & 0.36 & 0.62 & $=----$ \\
\hline MNM & 3.84 & 3.14 & 2.99 & 1.96 & 1.44 & 1.72 & 10 \\
\hline FBT & 2.69 & 2.23 & 2.18 & 1.62 & 1.29 & 1.28 & | \\
\hline Tex & 2.89 & 2.99 & 2.62 & 2.20 & 1.84 & 1.83 & $\mathbf{D}=--$ \\
\hline Gar & 2.84 & 2.91 & 2.68 & 1.92 & 1.62 & 1.52 & $\mathbf{\square}=-ー$ \\
\hline $\mathrm{TF}$ & 3.00 & 2.58 & 2.37 & 1.89 & 1.49 & 1.64 & I!n-ーー \\
\hline Pap & 3.23 & 2.62 & 2.34 & 1.94 & 1.50 & 1.82 & घอーーー \\
\hline $\mathrm{PC}$ & 2.84 & 2.16 & 1.77 & 1.02 & 0.88 & 0.86 & an--- \\
\hline $\mathrm{CP}$ & 2.86 & 2.47 & 2.38 & 1.86 & 1.46 & 1.41 & | $=$ =- \\
\hline NMP & 8.23 & 7.31 & 5.87 & 4.99 & 3.82 & 3.63 & $\mathbf{\square}=-ー$ \\
\hline MP & 3.97 & 3.79 & 3.41 & 2.50 & 2.14 & 2.47 & an-ー- \\
\hline Equ & 2.98 & 2.45 & 2.39 & 1.79 & 1.46 & 1.58 & I!日ーーー \\
\hline Was & 0.07 & 0.14 & 0.11 & 0.57 & 1.20 & 1.31 & $--=0$ \\
\hline ESW & 14.74 & 11.46 & 9.87 & 10.91 & 9.27 & 8.15 & 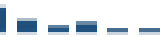 \\
\hline Gas & 3.29 & 3.27 & 2.97 & 1.84 & 1.32 & 1.40 & | \\
\hline TW & 6.86 & 4.19 & 4.03 & 2.01 & 1.75 & 2.33 & $1=0--$ \\
\hline Con & 4.11 & 3.52 & 3.22 & 3.22 & 2.50 & 2.00 & 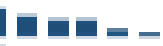 \\
\hline Tra & 3.89 & 2.60 & 2.76 & 1.94 & 1.68 & 1.87 & $1=\Xi---$ \\
\hline WRC & 2.37 & 1.85 & 1.74 & 1.15 & 1.15 & 1.25 & 1E=-ー \\
\hline Ser & 2.61 & 1.69 & 1.72 & 1.05 & 0.93 & 0.98 & $1=--$ \\
\hline Con & 2.50 & 2.14 & 2.59 & 1.52 & 1.26 & 1.37 & $1 \mathrm{a}=-$ \\
\hline
\end{tabular}

The influence of each component could be assessed using $W_{j}$ could assess the influence of upstream sectors on downstream ones. The ecological hierarchy of the urban metabolic system would be obtained from both pulling and driving perspectives. 


\subsection{Data Sources}

In this study, the urban metabolic system being modelled represents the socioeconomic system of Guangdong Province. Carbon emissions are taken into account within the geographical and administrative boundaries. With similar characteristic, socioeconomic sectors are emerged into 22 sectors. agriculture (Agr), mining (EM), ferrous and nonferrous metals mining (MNM), food, beverage and tobacco production (FBT), textile industry (Tex), garments and other fiber products (Gar), timber and furniture manufacturing (TF), papermaking, printing and educational articles (Pap), petroleum processing and coking (PC), chemical products (CP), nonmetal mineral products (NP), metal products (MP), equipment (Equ), scrap and waste (Was), electricity-generation (ESW), production and supply of gas (Gas), production and supply of tap water (TW), construction (Con), transportation (Tra), wholesale, retail trade and catering services (WRC), service (Ser), and domestic consumption (Dom). Analogy with the natural ecosystem could inspire the aggregation of 22 sectors into eight industries: agriculture (A), mining $(\mathrm{M})$, primary manufacturing $(\mathrm{PM})$, energy transformation (E), advance manufacturing (AM), tertiary industry (T), construction (C) and domestic consumption (Dom). Specific classification can refer to Table S1.

These sectors are defined as nodes in the network and defined the carbon emission flows between sectors as paths between the nodes, leading to the establishment of CEN model to facilitate the analysis of the integral carbon emissions. In an urban metabolic system, bidirectional carbon emission flows exist between any two sectors, that is, exchanges between pairwise sectors would result in the emission of carbon dioxide. Taking the data of 2000 as an example, Figure 1(a) shows the carbon emission flows between pairwise sectors. There are great differences in the flows among various sectors. Direct emissions of Equ are the highest followed by ESW and Dom. In the contrast, direct emissions of Was is the relevantly low, as well as TW, Gas, and Con. Paths in the network represents the values of emissions flows within the ecosystem. Figure 1(b) shows the carbon emissions generated by the interactions of Ser with other sectors. Service sector consumes large amounts of emission-intensive products to satisfy its final demand.

Economic input-output tables of 2000, 2002, 2005, 2007, 2010 and 2012 are used to gain the monetary flows between sectors. Besides, the method firstly introduced by Leontief could realize the compiling from monetary input-output tables into physical input-output tables during the study period. The initial data of carbon emissions could be obtained from the Statistical Yearbook of Guangdong Province released officially in relevant years. Particularly, since domestic consumption contributes significantly to carbon emissions and is closely related to industrial sectors, Dom is also considered as a sector in the emission network model.

\section{Results and Discussion}

\subsection{Carbon Metabolism Network of Guangdong Province}

Taken the year of 2012 as an example, carbon emission flows between various sectors are displayed in Figure 1. Different color represents different sectors. The width of flows represents the flow magnititude between various sectors. As shown in Figure 1(a), electricity and manufacturing sectors transfer more carbon emissions than other sectors. Emission flows between service and electricity sectors are large. Specifically, manufacturing sector has consumed large amounts of emissionintensive products produced by itself. Tertiary industry develops rapidly with more than $30 \%$ carbon emissions of the total in Guangdong Province. Carbon emission flows between service and other sectors are displayed in Figure 1(a).

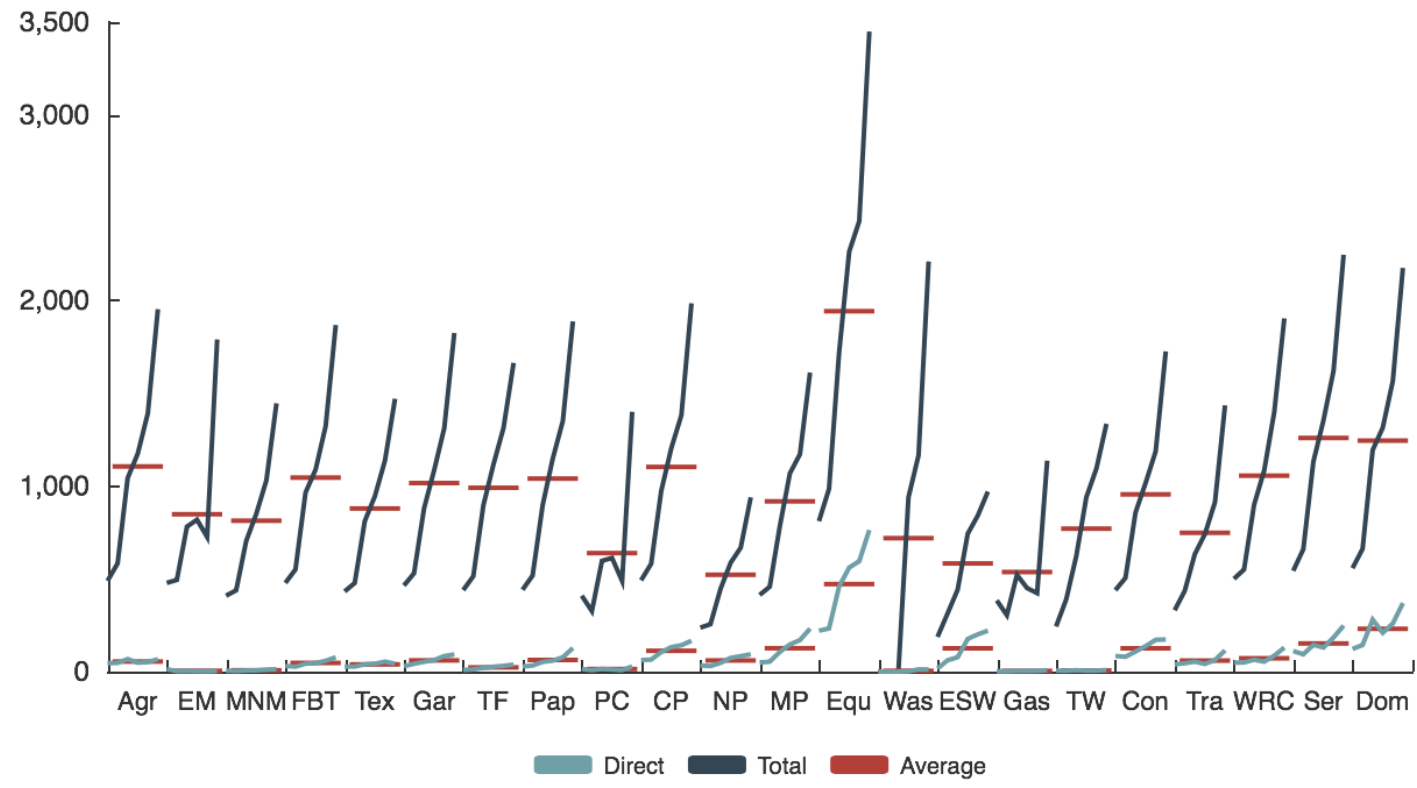

Figure 2. Direct, indirect carbon emissions of various economic sectors from 2000 to 2012 (Unit: Mt). 

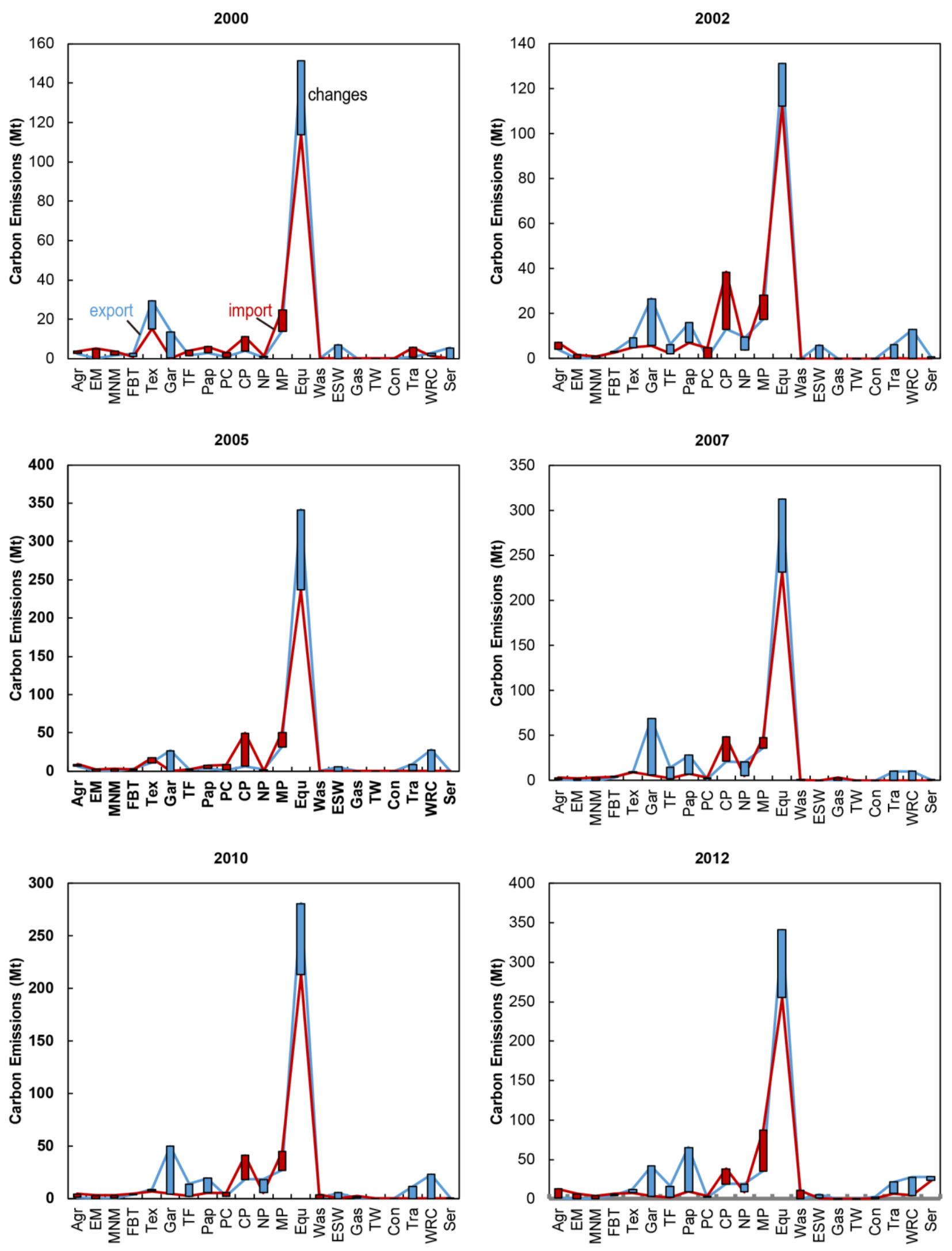

Figure 3. Imports, exports and their changes of Guangdong province from 2000 to 2012. 

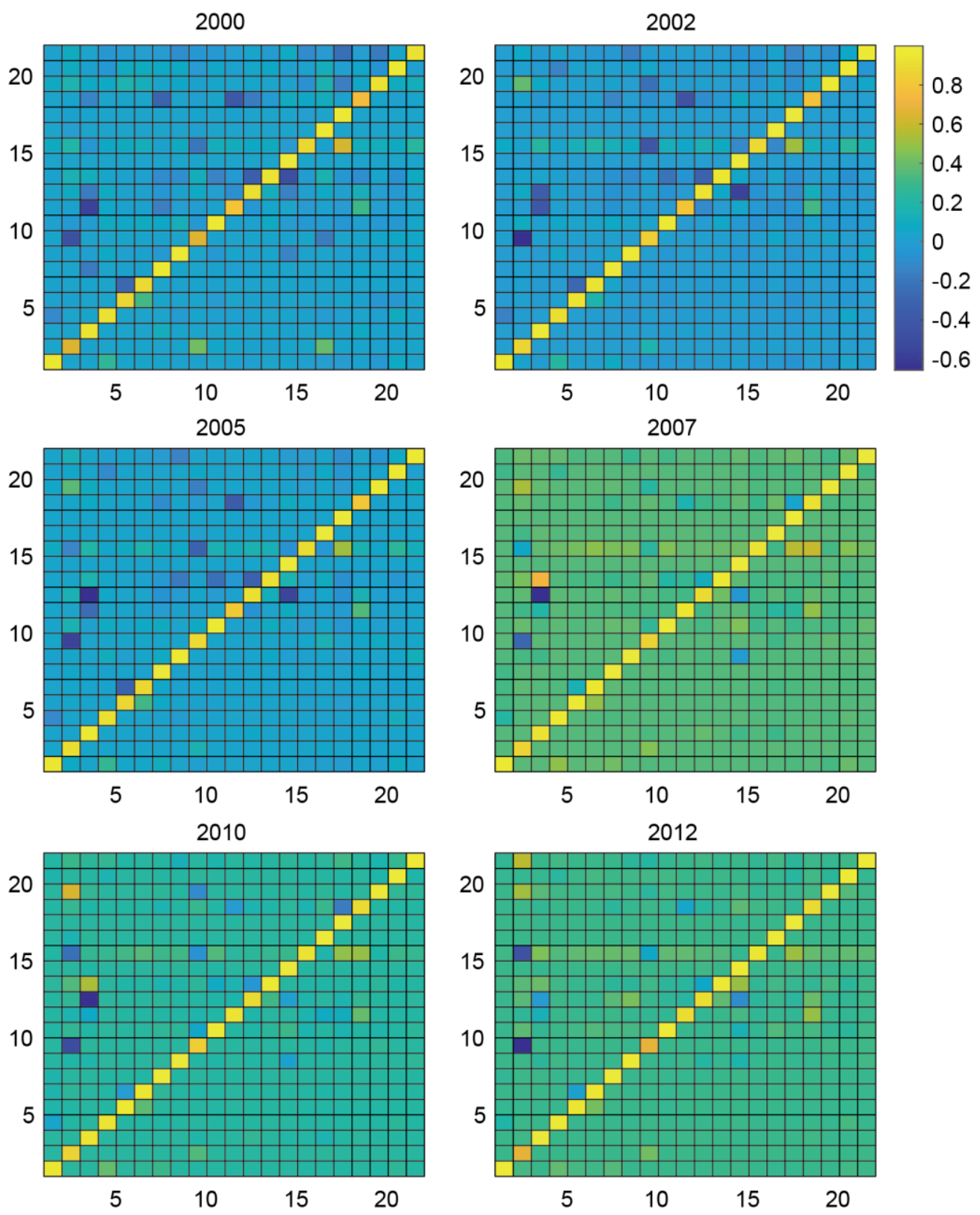

Figure 4. Mutual relationship between economic sectors from 2000 to 2012.

Figure 2 shows direct and indirect carbon emissions of economic sectors from 2000 to 2012. Direct emissions of electricity and manufacturing sectors are the largest during study period, followed by metal, service and construction sectors. Indirect emissions are substantially larger than the direct ones. Majority of sectors have shown an increasing trend during 2000 to 2012, except sectors of mining, petroleum processing, and gas production. Results show that indirect emissions should be taken into consideration when formulating emission mitigation policies.

Direct emission intensity from 2000 to 2012 are displayed in Table 1. With the development of clean production technology and the utilization of renewable energy, carbon emission intensity of economic sectors shows a decreasing trend while that of scrap and waste sector keeps an increasing trend. Electricity generation sector holds the largest carbon emission intensity, followed by nonmetal mineral production, water supply and construction sectors. Results show that substitution of renewable energy for fossil fuels, expansion of renewable generation installed capacity, development of cleaner production technologies can accelerate the low-carbon transition of Guangdong.

Figure 3 shows imports, exports and their changes of Guangdong Province from 2000 to 2012. Manufacturing sector exports and imports the most during these years, with its exports substantially larger than imports. Tertiary industry, i.e., 


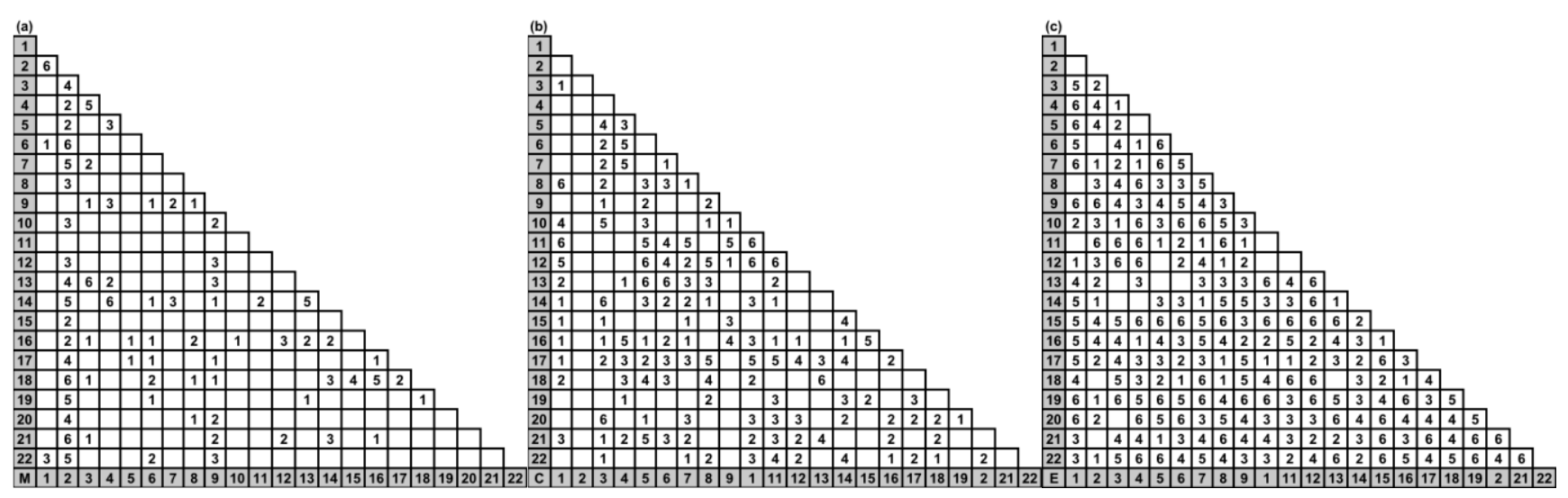

Figure 5. The number of mutual relationships between economic sectors during 2000 to 2012: (a) Mutualism relationship; (b) Competition relationship; (c) Exploitation relationship.

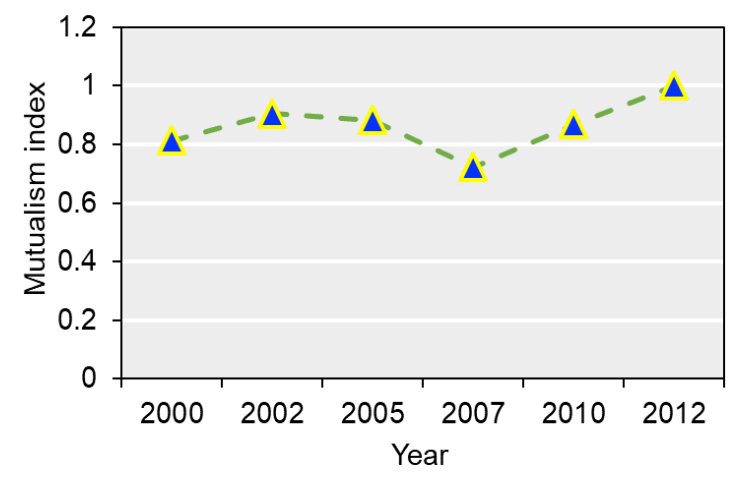

Figure 6. Mutualism index from 2000 to 2012.

service, textile and garment-production sectors, of Guangdong Province is developed, with large exports and small imports. Guangdong Province has provided large amounts of clothes for the whole country. On the contrary, chemical and metal production sectors consume more import-reliant products. Their imports are critically larger than exports. Agriculture sector imports more products than exports, for the reason that Guangdong Province has less cultivated land, and crops mainly rely on imports.

\subsection{Mutual Relationship between Economic Sectors}

Detailed relationships between pairwise sectors are displayed in Figure 4. Exploitation/control relationships dominate the system with a share of more than $50 \%$ during investigated years. There are more mutualism relationships (facilitating the emissions) than competition relationships (conductive for emission reduction) within the ecological system. For instance, nonmetal production sector has held a competition relationship with other sectors during the study period. For negative element, competition relationship is positive in achieving emission mitigation goal. Such that, production activities between such sectors should be maintained. Mutualism relationship is the dominant relationship between $\mathrm{CP}$ and other 12 sectors during study period. For negative substance, trade between these two sectors would reinforce the emission of carbon emissions.
CP sector should adjust both its production and consumption activites to improve their relationships. Specifically, upstream sectors, providing products to downstream sectors, are exploited along supply chains. These sectors should improve their clean production technologies to accelerate their green transition. In addition, downstream sectors and consuming products from upstream sectors exploit other sectors. These sectors need to adjust their consumption behavior and consume less emission-intensive products. As shown in Figure 5, exploitation/ control relationship is the dominant relationship among these three relationships.

Mutualism index could reveal the stability of carbon metabolism system (Figure 6). It keeps an increasing trend during the study period except 2017. For negative element, i.e., carbon emissions, system would be stable if mutualism index is less than 1 . On the contrary, system would be stable if mutualism index is more than 1 for positive elements. Results show that Guangdong Province has been kept stable these years, and its metabolic efficiency is relatively low.

With the ecological system, ecological hierachy shows a regular pyramid from 2000 to 2012 . It indicates that the driving force of upsteam sectors on downstream sectors is sufficient. As shown in Figure 7(a), driving force of upstream sectors are larger than that of downstream sectors. The driving force of $\mathrm{PM}+\mathrm{E}, \mathrm{AM}, \mathrm{T}$ and $\mathrm{C}+\mathrm{D}$ sectors on downstream sectors are efficient. Specifically, agriculture and mining sectors pull their downstream sectors insufficiently. It indicates that Guagndong develops secondary and tertiary industries instead of the primary industry. From the perspective of sale chains, Guangdong is in a stable state with sufficient driving force.

Ecological hierarchy exhibits an irregular pyramid during the study period. As shown in Figure 7 (b), the pulling force of primary manufacturing and electricity-generation sectors are sufficient, with large demands of goods and services from upstream sectors. The pulling force of tertiary industry is insufficient, as well as construction and domestic consumption. Their ability to pull economic development is still inadequate. Specifically, the pulling force of advanced manufacturing sectors is insufficient in 2005 . It indicates that the tertiary industry has 

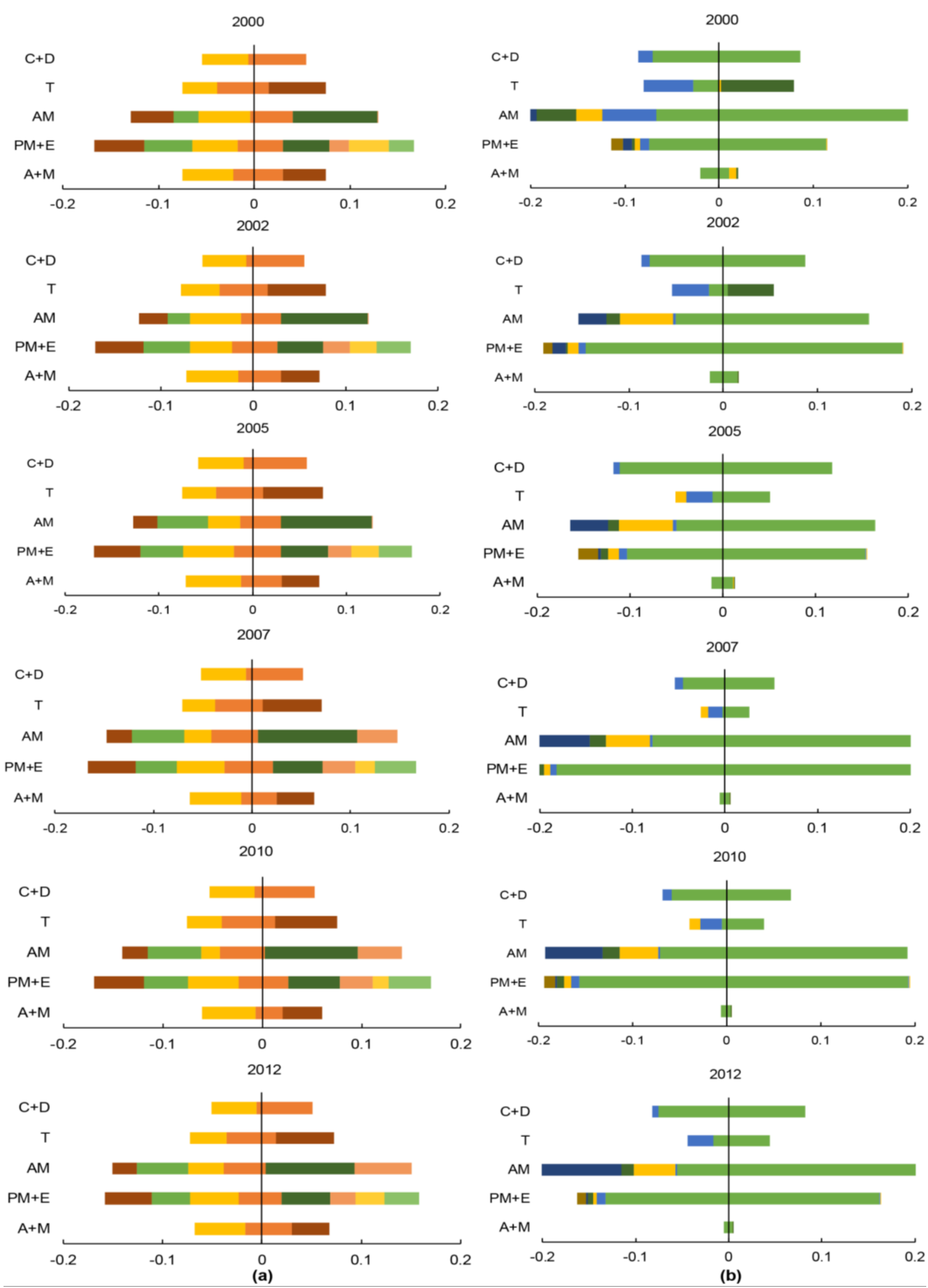

Figure 7. (a) Driving force of economic sectors from 2000 to 2012; (b) Pulling force of economic sectors from 2000 to 2012. 


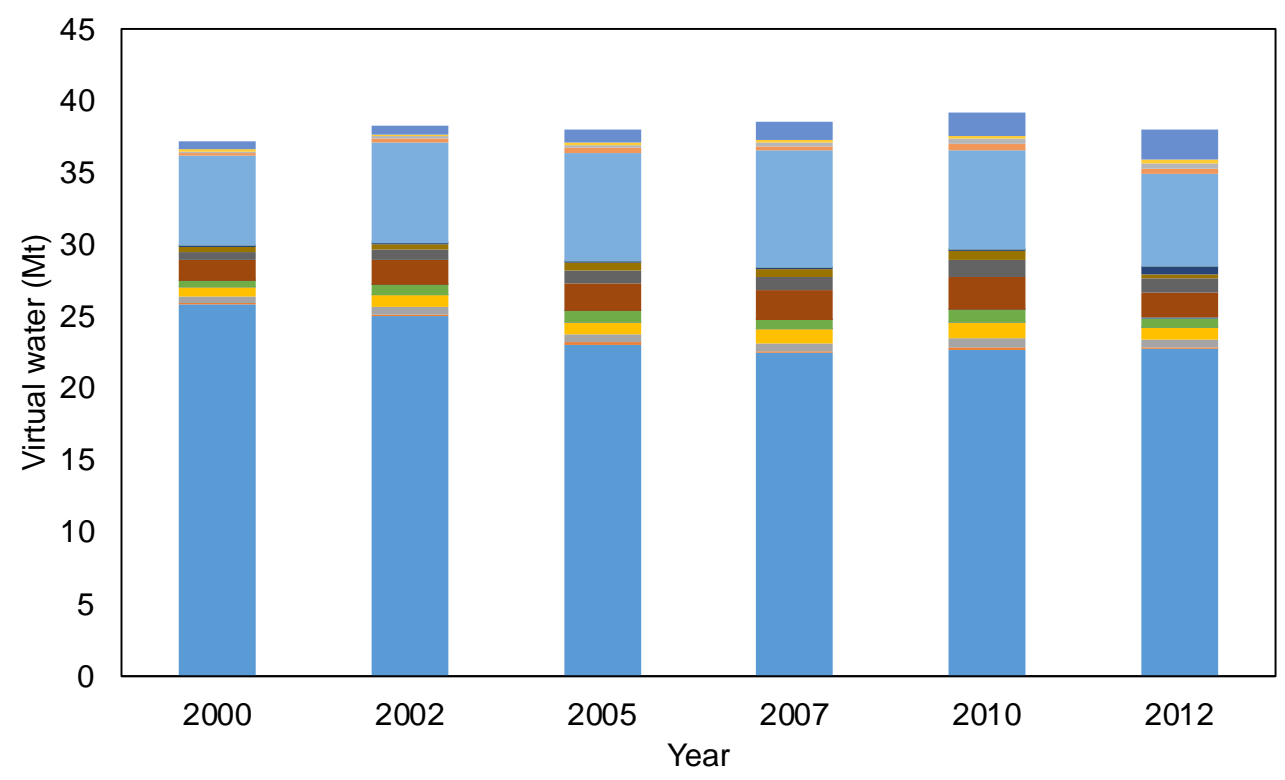

Figure 8. Virtual water of Guangdong Province from 2000 to 2012.

not dominated the economic development of Guangdong Province. Development of the Tertiary industry could help Guangdong Province to keep in healthy state.

As shown in Figure 8, virtual water of Guangdong Province changes slightly from 2000 to 2012 . Virtual water consumption peaked in 2010 and then showed a downward trend till 2012. Agriculture sector consumes the largest virtual water, followed by electricity-generation sector. Results show that metabolism of various ecological elements is significantly different.

\section{Conclusions}

The innovation of this research is to get a holistic assessment of the carbon dioxide metabolism among economic sectors of Guangdong Province, and give a comparison of ecological hierarchy from bottom-up and top-down perspectives. In detail, an ENA-related carbon metabolism model is developed to assess the healthy degree of socioeconomic system. Implied sectors with large indirect emissions would be identified and corresponding suggestions would be proposed to achieve the emission mitigation goal. Moreover, ecological hierarchy (i.e., pulling and driving force) would be assessed. This study would help formulate target policies on emission mitigation policies. Guangdong should develop its Tertiary industry to improve the pulling force along supply chains. Incentive policies should be proposed to enlarge the demands of construction sector and domestic consumption. It is conducive to the healthy development of Guangdong Province.

Acknowledgements. This research was supported by the National Key Research and Development Plan (2016YFA0601502, 2016YFC0502800) and the Natural Science and Engineering Research Council of Canada. We are also very grateful for the helpful inputs and suggestions from the Editor and anonymous reviewers.

\section{References}

Abdehvand, M.Z., Roknizadeh, S.A.S. and Mohammad-Sedighi, H. (2021). Modeling and analysis of novel coupled magneto-electroaeroelastic continuous system for flutter-based energy harvesting system. Energy. 230. https://doi.org/10.1016/j.energy.2021.120742

Asif, Z. and Chen. Z. (2020). A life cycle based air quality modeling and decision support system (LCAQMS) for sustainable mining management. Journal of Environmental Informatics. 35(2), 103117. https://doi.org/10.3808/jei.201900406

Chaudhuri, S., Roy, M. and Jain, A. (2020). Appraisal of WaSH (WaterSanitation-Hygiene) infrastructure using a composite index, spatial algorithms and sociodemographic correlates in rural India. Journal of Environmental Informatics. 35(1), 1-22. https://doi:10.3808/jei.2 01800398

Chen, S.Q. and Chen, B. (2017). Changing urban carbon metabolism over time: Historical trajectory and future pathway. Environmental Science \& Technology. 51(13), 7560-7571. https://doi.org/10.1021 /acs.est.7b01694

Chen, S.Y., Liu, P. and Li, Z. (2020a). Low carbon transition pathway of power sector with high penetration of renewable energy. Renewable and Sustainable Energy Reviews. 130, 109985. https://doi. org/10.1016/j.rser.2020.109985

Chen, S.Q., Long, H.H., Fath, B.D. and Chen, B. (2020b). Global urban carbon networks: Linking inventory to modeling. Environmental Science \& Technology. 54(9), 5790-5801. https://doi.org/10. 1021/acs.est.0c00965

Dai, J., Chen, B. and Sciubba, E. (2014). Ecological accounting based on extended exergy: A sustainability perspective. Environmental Science \& Technology. 48(16), 9826-9833. https://doi.org/10.1021/ es404191v

Feng, Y.Y., Chen, S.Q. and Zhang, L.X. (2013). System dynamics modeling for urban energy consumption and $\mathrm{CO}_{2}$ emissions: A case study of Beijing, China. Ecological Modelling. 252, 44-52. https:// doi.org/10.1016/j.ecolmodel.2012.09.008

Guan, Y.R., Huang, G.H., Liu, L.R., Zhai, M.Y. and Zheng, B.Y. (2019). Dynamic analysis of industrial solid waste metabolism at aggregated and disaggregated levels. Journal of Cleaner Production. 221, 817-827. https://doi.org/10.1016/j.jclepro.2019.01.271

Leontief, W.W. (1936). Quantitative input and output relations in the economic system of The United States. Review of Economic Statis- 
tics. 18, 105-125. https://doi.org/10.2307/1927837

Li, J.Z., Huang, G.H., Li, Y.P., Liu, L.R. and Sun, C.X. (2021a). Unveiling carbon emission attributions along sale chains. Environmental Science \& Technology. 55(1), 220-229. https://doi.org/10.1021/ acs.est.0c05798

Li, J.Z., Huang, G.H. and Liu, L.R. (2018). Ecological network analysis for urban metabolism and carbon emissions based on inputoutput tables: A case study of Guangdong province. Ecological Modelling. 383, 118-126. https://doi.org/10.1016/j.ecolmodel.2018. 05.009

Li, W., Bazant, M.Z. and Zhu, J. (2021b). A physics-guided neural network framework for elastic plates: Comparison of governing equations-based and energy-based approaches. Computer Methods in Applied Mechanics and Engineering. 383. https://doi.org/10.1016/j. cma.2021.113933

Li, Y., Shen, J.Y., Xia, C.Y., Xiang, M.T., Cao, Y. and Yang, J.Y. (2021c). The impact of urban scale on carbon metabolism - a case study of Hangzhou, China. Journal of Cleaner Production. 292. https://doi.org/10.1016/j.jclepro.2021.126055

Patten, B.C. (1992). Energy, emergy and environs. Ecological Modelling. 62(1-3), 29-69. https://doi.org/10.1016/0304-3800(92)90081-O

Roberts, J.L., Tozer, C.R., Ho, M., Kiem, A.S., Vance, T.R., Jong, L.M., McCormack, F.S. and van Ommen, T.D. (2020). Reconciling unevenly sampled paleoclimate proxies: A Gaussian Kernel correlation multiproxy reconstruction. Journal of Environmental Informatics. 35, 118-127. https://doi:10.3808/jei.201900420

Shrestha, N.K. and Wang, J. (2020). Water quality management of a cold climate region watershed in changing climate. Journal of Environmental Informatics. 35(1), 56-80. https://doi.org/10.3808/jei.20 1900407

Wang, X., Wang, P.F., Wang, C., Chen, J., Hou, J., Miao, L.Z., Feng, T. and Yuan, Q.S. (2020a). Taxonomic and functional responses of sediment bacterial community to anthropogenic disturbances in the Yarlung Tsangpo River on the Tibetan Plateau. Journal of Environmental Informatics. 35(1), 23-33. https://doi:10.3808/jei.201800403

Wang, Y., Mauree, D., Sun, Q., Lin, H.J., Scartezzini, L. and Wennersten, R. (2020b). A review of approaches to low-carbon transition of high-rise residential buildings in China. Renewable and Sustainable Energy Reviews. 131. https://doi.org/10.1016/j.rser.20 20.109990

Wang, Z., Wei, L.Y., Niu, B.B., Liu, Y. and Bin, G.S. (2017). Controlling embedded carbon emissions of sectors along the supply chains:
A perspective of the power-of-pull approach. Applied Energy. 206, 1544-1551. https://doi.org/10.1016/j.apenergy.2017.09.108

Wei, T. and Chen, S.Q. (2020). Dynamic energy and carbon footprints of urban transportation infrastructures: Differentiating between existing and newly-built assets. Applied Energy. 277. https://doi.org/ 10.1016/j. apenergy.2020.115554

Wu, H.P., Chen, J., Zeng, G.M., Xu, J.J., Sang, L.H., Liu, Q., Dai, J., Xiong, W.P., Yuan, Z., Wang, Y.Q. and Ye, S.J. (2020). Effects of early dry season on habitat suitability for migratory birds in China's two largest freshwater lake wetlands after the impoundment of Three Gorges Dam. Journal of Environmental Informatics. 36(2), 82-92. https://doi:10.3808/jei.201900411

Yu, B.Y., Wu, P., Sui, J., Ni, J. and Whitcombe, T. (2020). Variation of runoff and sediment transport in the Huai River - a case study. Journal of Environmental Informatics. 35(2), 138-147. https://doi. org/10.3808/jei.202000429

Zhang, X.M., Zhou, M., Li, J.H., Wei, L.Y., Dong, Y.Q., Hou, H.B., Chen, C. and Wang, Z. (2021a). Analysis of driving factors on China's industrial solid waste generation: Insights from critical supply chains. Science of the Total Environment. 775. https://doi. org/10.1016/j.scitotenv.2021.145185

Zhang, Y., Fu, Z.H., Xie, Y.L., Li, Z., Liu, Y.X., Zhang, B.C. and Guo, H.C. (2021b). Dynamic metabolism network simulation for energywater nexus analysis: A case study of Liaoning Province, China. Science of the Total Environment. 779. https://doi.org/10.1016/j.sci totenv.2021.146 440

Zhang, Y., Li, Y.G., Liu, G.Y. and Hao, Y. (2018). $\mathrm{CO}_{2}$ metabolic flow analysis in global trade based on ecological network analysis. Journal of Cleaner Production. 170, 34-41. https://doi.org/10.1016/j.jc lepro.2017.08.244

Zheng, B.Y., Huang, G.H., Liu, L.R., Zhai, M.Y. and Guan, Y.R. (2019). Metabolism of urban wastewater: Ecological network analysis for Guangdong Province, China. Journal of Cleaner Production. 217, 510-519. https://doi.org/10.1016/j.jclepro.2019.01.222

Zheng, B.Y., Huang, G.H., Liu, L.R., Zhai, M.Y. and Li, Y.P. (2020). Two-pathway perspective for heavy metal emission mitigation: A case study of Guangdong Province, China. Science of the Total Environment. 735. https://doi.org/10.1016/j.scitotenv.2020.139583

Zheng, B.Y., Huang, G.H., Liu, L.R., Zhai, M.Y. and Li, Y.P. (2021). Inter- regional cluster analysis of heavy-metal emissions. Journal of Cleaner Production. 282. https://doi.org/10.1016/j.jclepro.2020.12 4439 